To the paper

\title{
Aluminium-26: A nuclide for all seasons
}

\author{
T. P. Kohman \\ Department of Chemistry. Carnegie-Mellon University, Pittsburgh, PA 15213, USA
}

(Received March 12, 1997)

appeared in the Journal of Radioanalytical and Nuclear Chemistry, 219, No. 2 (1997) 165-176. On page 174, to the acknowledgements, the followings should be added:

Fig. 2 from Geochim. Cosmochim. Acta 14, 340-63, W. D. Ehmann and T. P. Kohman, "Cosmic-ray-induced radioactivities in meteorites-I. Chemical and radiometric procedures for aluminum, beryllium, and cobalt" (@ 1958); Fig. 5 from idem. Suppl. 1, Proc. Apollo 11 Lun. Sci. Conf., 1455-69, R. W. Perkins, L. A. Rancetelli, J. A. Cooper, J. H. Kaye and N. A. Wogman, "Cosmogenic and primordial radionuclide measurements in Apollo 11 lunar samples by nondestructive analysis" (@ 1970) and Fig. 11 from idem, Suppl. 10, Proc. Ninth Lun. Plan. Sci. Conf., 1345-68, I. D. Hutcheon, I. M. Steele, J. V. Smith and R. N. Clayton, "Ion microprobe, electron microprobe and cathodoluminescence data for Allende inclusions with emphasis on plagioclase chemistry" (๑ 1978), are reprinted with kind permission from Elsevier Science Ltd., The Boulevard, Langford Lane, Kidlington 0X5 IGB, UK.

Fig. 3 is reprinted with permission of Verlag der Zeitschrift für Naturforschung, Tübingen, Germany.

Fig. 4 is reprinted with the permission of the author and the implicit permission of the American Institute of Physics, New York, New York.

Fig. 6 from Nucl. Inst. Meth. Phys. Sci., B52, 370-4, J. R. Southon, D. E. Nelson and J. S. Vogel, "Injection systems for AMS: simultaneous versus sequential" (() 1990) and Fig. 20 from idem B92, 478-82, C. Hohl, G. Gerisch, G. Korschinek, E. Nolte, T. H. Ittel, "Medical applications of ${ }^{26} \mathrm{Al} "$ (๔ 1994), are reprinted with kind permission from Elsevier Science-NL, Sara Burgerhartstraat 25, $1055 \mathrm{KV}$ Amsterdam, The Netherlands.

Figs 7,9 and 10 are reprinted with permission of K. C. Welten.

Figs 12,13 and 14 are reprinted with the permission of Meteoritics and Planetary Science, University of Arkansas, Fayetteville, Arkansas and the consent of G. MacPherson.

Figs 15 and 16, (-) 1984 and 1987, respectively, The American Astronomical Society, are reprinted with the permission of W. A. Mahoney and P. von Ballmoos, respectively and the University of Chicago Press, Chicago, Illinois.

Fig. 17 is reprinted with permission of Astronomy and Astrophysics, Paris, France.

Figs 18 and 19 are reprinted with permission of the American Journal of Physiology, Bethesda, Maryland. 